\title{
Analysis of the Spatial Effect of Provincial Fiscal Transparency on FDI in China
}

\author{
Ying $\mathrm{Li}^{1 . \mathrm{a}} \quad$ Ming $\mathrm{Na}^{1 . \mathrm{b}_{*}}$ \\ ${ }^{1}$ School of Economics, HeFei University of Technology, Hefei 230601, China \\ ajasmine.na@163.com, byingzi0906@126.com
}

Keywords: Fiscal transparency; foreign direct investment; spatial effect

\begin{abstract}
In promoting fiscal transparency, China's various provinces care too much about "next door neighbor" view and behavior; neither of them wants to "go too further". Taking the spatial effect into consideration and comparing the three models, OLS, SLM and SEM, this paper explores the spatial correlation between various provinces' fiscal transparency and the impact of fiscal transparency on FDI. The result shows that there is a significant positive spatial correlation between various provinces' fiscal transparency, and fiscal transparency has spatial dependence on FDI in China, which is reflected in the error term; for the coefficient value of the SEM, $1 \%$ change of fiscal transparency would cause $1.4686 \%$ change of FDI, which indicates that in China promoting fiscal transparency can play a positive role in optimizing investment environment and attracting foreign capital. The paper finally proposes relative suggestions to improve fiscal transparency to attract foreign investment to China.
\end{abstract}

\section{Introduction}

Over the past 20 years, the global economic and financial crises are almost all related to debt, so that people realize that the lack of fiscal transparency is the root cause of the crises ${ }^{[1][2][3][4]}$. In November 2012, IMF called on that the world should redouble their efforts to improve fiscal transparency, and stressed the monitoring efforts of the strengthening of member states' fiscal transparency. Therefore, fiscal transparency is the manifestation of a government's good governance and citizen's right. Improving fiscal transparency to solve the problem of information asymmetry can make citizens better understand and monitor the budget decision-making, so that the government's fiscal revenue and expenditure can better reflect the wishes of people and reduce the risk of agency. Therefore, the importance of fiscal transparency has been widely recognized in academia [5] [6] [7] [8] [9] [10] [11], and it is an important prerequisite for macroeconomic stability, good governance and financial fairness.

Research shows that the increase of fiscal transparency can bring about the increase of foreign investment, and the increased foreign investment can be transformed into more resources, which will in turn leads to the increase of social wealth and economic efficiency ${ }^{[10]}$. Thus, the fiscal transparency level is an important factor of attracting foreign investment. Petrie ${ }^{[11]}$ pointed out that the act of government publicizing its fiscal information and intention can help to improve its ability of financing from international capital market. Moreover, when a financial crisis occurs, the probability that foreign investment flees from countries with a low fiscal transparency level is much higher than from those countries with a high fiscal transparency level ${ }^{[12]}$. This theory has been widely recognized in a couple of financial crises that the timely and complete disclosure of fiscal information can avoid the volatility of financial market. The IMF managing director, M. Camdessus, pointed out that fiscal transparency is "the golden rule" of a nation's financial system, and opaque information could wink at corruption, increase the hidden costs of foreign investment, and raise investment risk and subsequently impede the free flow of investment.

Based on the above analysis, this paper speculates that the low fiscal transparency level of a country would lead to capital market uncertainty, information asymmetry and increase of extra transaction cost, and would further push FDI out to more transparent countries or regions. To test this hypothesis, this paper will explore the impact of fiscal transparency on FDI empirically with the calculated index system of China's fiscal transparency. Based on provincial samples, this paper will answer the questions whether the fiscal transparency level is a determinant of foreign direct 
investment to China, and whether FDI flows to more transparent provinces and cities.

\section{Methodology}

\subsection{Structure of the Model.}

In order to verify the hypothesis proposed above, this paper will adopt the classic model of foreign investment behavior constructed by Zdenek D., Warren P. ${ }^{[12]}$, which is presented as follows:

$$
\mathrm{FDI}=\mathrm{f}(\mathrm{FT}, \mathrm{Y}, \mathrm{r}, \mathrm{i}, \mathrm{ER}, \mathrm{TR}, \mathrm{C})
$$

Among which, FT is fiscal transparency; $\mathrm{Y}$ is economic development (GDP); $r$ is interest rate; $\mathrm{i}$ is inflation; ER is exchange rate; TR is trade system openness; $\mathrm{C}$ is country, a dummy variable.

Because the study area of this paper is China's various provinces and cities, variables such as interest rate, inflation, exchange rate, trade system openness are of no difference between provinces and cities. Therefore, the theoretical model is adapted to the following form:

$$
\mathrm{FDI}=\mathrm{f} \text { (FT, gdp) }
$$

In terms of quantitative methods, the existing research on the effect of fiscal transparency often neglects the influence of spatial heterogeneity and spatial dependence on fiscal transparency, but fiscal transparency often has the "looking at the next-door neighbor" attribute. For example, in 2013, right after Prof. Yu Qiao from Public Management School of Tsinghua University published China's Municipal Fiscal Transparency Report, Wang Wenchao, the director in Budget Office of Hangzhou Finance Bureau said at once that when they practice fiscal information transparency, they need to look at the next-door neighbors. "We can't fall behind, but if they do not go, we can't go too much further”. His statement implies that there exists spatial dependence between various provinces' fiscal transparency. The existence of spatial dependence challenges the basic assumption of mutual independence in the classic statistics and econometric analysis, and breaks the assumption that the intercept in a regression model is constant. If the classic statistical theory is directly applied to spatial data analysis, that will cause the ordinary least square (OLS) to fail in analysis, and make the estimated result biased. However, spatial econometrics incorporates the relationship between regions concerned in the model, modifies the classic linear regression model through spatial weight matrix, fully takes into consideration the interdependence between regions, and thus improves the robustness of a correlation test, and makes the estimated result more reliable. Therefore, according to the estimation techniques of the spatial model, the theoretical model in this paper will be constructed as bellow:

(1) Using the OLS to estimate the relationship between fiscal transparency and FDI, the model is as follows:

$$
\operatorname{lnFDI}=\beta_{0}+\beta_{1} F T+\beta_{2} G D P+\varepsilon
$$

(2) Based on the estimation techniques of the spatial lag model (SLM) and spatial error model (SEM), this paper will establish the SLM model and SEM model, and compares their estimated result with the OLS model estimated result.

$$
\text { SLM model: } \quad \operatorname{lnFDI}=\rho w \operatorname{lnFDI}+\beta_{0}+\beta_{1} F T+\beta_{2} G D P+\varepsilon \quad \varepsilon \sim N\left(0, \sigma^{2}\right)
$$

Among them, $w$ is an $\mathrm{N}_{*} \mathrm{~N}$ spatial weight matrix; $w \operatorname{lnFDI}$ is the spatially lagged dependent variable, reflecting whether the dependent variable has spillover effect in the area; $\rho$ is the coefficient reflecting the degree of spatial dependence between variables.

$$
\text { SEM model: } \operatorname{lnFDI}=\beta_{0}+\beta_{1} F T+\beta_{2} G D P+\varepsilon \quad \varepsilon=\lambda w \varepsilon+\mu \mu \sim N\left(0, \sigma^{2}\right)
$$

Among them, $\varepsilon$ is the random error vector; $w \varepsilon$ is the spatial lag of the random error; $\lambda$ is the coefficient representing the influence of spatial dependence on the error term.

\subsection{Data Sources.}

The variables in this paper include foreign direct investment (FDI), fiscal transparency (FT), and regional economic development level (GDP per capita). The fiscal transparency data was calculated in accordance to the author's survey in 2011 ${ }^{[13]}$; the regional economic development level is represented by regional GDP per capita, acquired by dividing the 2011 regional GDP by the local population. For the explanatory variable, FDI, compared with fiscal transparency, is a lagged 
variable, because foreign business will investigate a certain area's transparency level before investing in this country or area. Therefore in the circumstance that the fiscal transparency survey data have been given, in order to avoid data anomalies, this paper uses the average value of 2007-2011 provincial FDI to get it modified; the data are from the website of the Ministry of Commerce and are used in a logarithmic way.

\section{Spatial Autocorrelation Test of Fiscal Transparency to FDI}

Spatial correlation is based on the first law of geography that the attribute of a thing within a region is related to the attribute of the same thing within other regions. Before modeling, it is required to determine if a variable has spatial effect, and to test its spatial correlation.

\subsection{Spatial Weights Matrix.}

Spatial weight is an important characteristic of spatial econometrics differing from the traditional econometrics. Before doing spatial econometrics analysis, the first thing is to determine the spatial weight matrix, which is the basis and premise for spatial data analysis, and bridge between variables. "Spatial distance" and "economic distance" are commonly used in spatial econometrics. Using "economic distance" to describe the spatial relationship between area units is more in line with the economic operating environment; therefore, "economic distance" weight is more scientific than "spatial distance". However, when it comes to the availability of data, and the computational complexity and exogeneity of spatial weight, "contiguity weight" is the most commonly used in weight setting, so this paper uses the "contiguity weight" method in weight setting and "Rook contiguity" to acquire spatial weight matrix for 30 provinces of China.

\subsection{Spatial Autocorrelation Test.}

This paper uses GeoDa to make a test on spatial autocorrelation between FDI and fiscal transparency, and FDI and GDP per capita, and make a test on the Moran's Index by Monte Carlo simulation. As seen from Table 1, all the P values pass the test; FDI in China is significant at the 1\% level; the Moran's Index is 0.1760 , significantly greater than 0 , which shows that there exists positive spatial correlation in the spatial distribution of FDI. From the Moran's Index scatter Fig. (Fig. 1 (1)), it can be seen that the spatial agglomeration of provincial FDI is obvious, mainly concentrated in the first and three quadrant. This occurrence supports the assumption that high value tends to get together with high value, and low value tends to get together with low value, that is, the FDI behavior in China has a positive spatial autocorrelation.

Table1 Spatial autocorrelation test

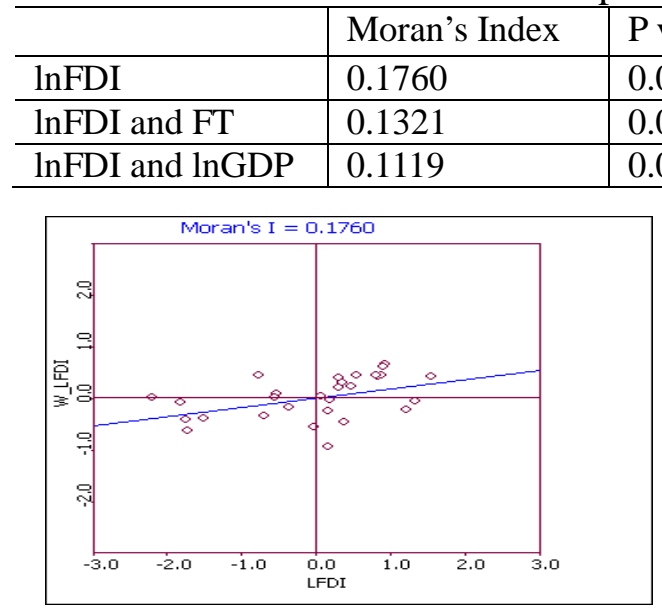

(1)

\begin{tabular}{l|l|l|l}
\hline P value & Expectation & Mean & Std. Deviation \\
\hline 0.0120 & -0.0345 & -0.0347 & 0.0817 \\
0.0010 & -0.0345 & -0.0363 & 0.0829 \\
0.0010 & -0.0345 & -0.0298 & 0.0778 \\
\hline
\end{tabular}

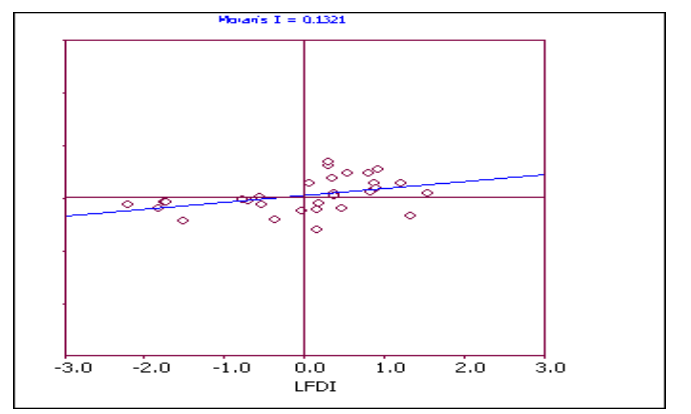

(2)

Fig. 1 Moran's Index scatter

From the spatial correlation multivariate test, the Moran's Index of fiscal transparency and FDI is 0.1321, and the Moran's Index of GDP per capita and FDI is 0.1119, both of which are significantly greater than 0, showing that there exist the high-high spatial agglomeration in spatial units (or low-low agglomeration), and also that it is feasible to incorporate these variables in the spatial econometric model. Additionally, as shown from the scatter diagram (Fig. 1 (2)), 80\% samples out 
of the 30 provinces and cities display similar spatial correlation (spots are mainly concentrated in the first and three quadrant). Therefore, from the overall perspective, fiscal transparency is an important factor to attract foreign investment to China, and the two variables are positively correlated in spatial distribution.

The value of the global Moran's Index can only roughly show whether there exists spatial autocorrelation on FDI, between FDI and fiscal transparency, and FDI and regional GDP per capita in the whole area, but it does not show what kind of the spatial correlation model it is. To solve this problem, in 1995 Anselin proposed the local indicator spatial association (LISA) method to measure the correlation degree between the neighborhood spatial units, making up the shortage of total spatial correlation.

According to the output of GeoDa, the value of the local spatial autocorrelation of Moran 's Index is 0.2271, greater than 0; its corresponding $\mathrm{P}$ value is 0.001 , passing the Monte Carlo simulation test, and indicating that the local spatial units in the vicinity are of high-high concentration or low-low concentration. At the 1\% significance level, the local spatial effect is significant in Hainan, Xinjiang, Gansu and Sichuan; at the 5\% significance level, the local spatial effect is significant in Qinghai, Hebei, Jiangsu, Jiangxi, Shanghai, Zhejiang, Anhui and Fujian as well. It indicates that the spatial effect is particularly prominent in the above provinces, and the influence of fiscal transparency on FDI is also varying among different areas.

\section{Results}

By the above global Moran's Index and local spatial correlation test, the result shows that there exists spatial correlation between FDI in China and fiscal transparency. This paper estimates the relationship between FDI and fiscal transparency, FDI and GDP per capita by using OLS model, spatial lag model (SLM) and spatial error model (SEM).

The paper uses the OLS to do the regression on the three variables, fiscal transparency, GDP per capita and FDI (the result can be seen from table 2). $\mathrm{R}^{2}$, the determination coefficient, is 0.5144 , showing that the explanatory variables, GDP per capita and fiscal transparency can explain FDI at the extent of $51.44 \%$; the F value is 13.2024 , but the AIC and SC values are quite large, which shows that the OLS model has poor fitting effect. For the regression coefficient, the constant is not significant; GDP per capita passes the test at the $1 \%$ significance level; the regression coefficient of fiscal transparency is 1.1731 , and its corresponding $\mathrm{P}$ value is 0.1076 at the $5 \%$ significance level, which indicates that the regression coefficient for fiscal transparency is not significant when the OLS model is used.

For the spatial dependence test, the spatial error effect is significant as the LMERR (Lagrange Multiplier error) and RLMEER models (Robust LM error) both pass the test at the $10 \%$ significance level; thus the result derived from the OLS model ignoring spatial effect is inaccurate or biased. For the tested result of spatial effect, the LMERR and RLMEER are more significant than LMLAG and RLMLAG, so according to the selection criteria proposed by Anselin ${ }^{[14]}$, the SEM model would be more appropriate. 
Table 2 Econometric estimates on OLS

\begin{tabular}{l|l|l|l|l}
\hline Independent variable & coefficient & Std.E & T-statistics & P Value \\
\hline intercept & -2.4726 & 4.2718 & -0.5788 & 0.5675 \\
\hline LFT & 1.1731 & 0.7048 & 1.6643 & 0.1076 \\
\hline LGDP & 2.9416 & 0.4919 & 3.9475 & 0.0005 \\
\hline & statistics & - & - & - \\
\hline $\mathrm{R}^{2}$ & 0.5144 & - & - & - \\
\hline $\mathrm{F}$ & 13.2024 & - & - & 0.1150 \\
\hline AIC & -91.9023 & - & - & - \\
\hline SC & 96.1239 & & & \\
\hline & MI/DF & Value & P-value & - \\
\hline Moran's I(error) & -0.1368 & -1.3862 & 0.0657 & - \\
\hline LMLAG & 1 & 0.0958 & 0.7568 & - \\
\hline R-LMLAG & 1 & 0.4281 & 0.5129 & - \\
\hline LMERR & 1 & 2.2567 & 0.1038 & - \\
\hline R_LMERR & 1 & 2.5803 & 0.0901 & - \\
\hline
\end{tabular}

This paper uses the SLM and SEM separately to test and estimate the effect of fiscal transparency and GDP per capita on China's provincial FDI, and adopts the maximum likelihood estimation method, and the result can been seen from table 3.

First, for the statistic result, the coefficients of determination of the three models, OLS, SLM and SEM, are 0.5144, 0.6015 and 0.7985 respectively; the SEM's fitting goodness is the best, showing that the model has been greatly improved after the spatial effect is taken into consideration. In addition, the AIC and SC values of the SEM were -6 and 10.2306 respectively, the smallest in the three models, which in a sense indicates that the SEM has a higher fitting degree than the other two models.

To summer up, through the comparison of the statistical result, it is apparent that the SEM has the best fitting effect, and the spatial effect existing in China's provincial FDI mainly lies in the error term. In other words, the spatial effect of foreign direct investment of China is not caused by themselves' interaction but by the impact of the overall characteristics of regional fiscal transparency and GDP per capita on the region and the adjacent regions. This further verifies that the result would be biased if the traditional statistical method is used to analyze the impact of fiscal transparency on FDI.

Table 3 Econometric estimates of SLM and SEM

\begin{tabular}{l|l|l|l|l|l|l|l|l}
\hline & \multicolumn{5}{|c}{ SLM } & \multicolumn{5}{c}{ SEM } \\
\hline Variable & coefficient & Std.E & Z-statistics & P-value & coefficient & Std.E & Z-statistics & P-value \\
\hline C & -0.665 & 15.430 & -0.0431 & 0.96 & -5.6051 & 3.5141 & -1.595 & 0.11 \\
\hline LFI & 1.8731 & 6.039 & 0.3101 & 0.7564 & 1.4686 & 0.5843 & 2.5437 & 0.10 \\
\hline LGDP & 4.1415 & 1.9611 & 2.1119 & 0.034 & 2.3576 & 0.4044 & 5.8291 & 0.00 \\
\hline WLNFDI & 1.7907 & 0.0623 & 28.716 & 0.000 & - & - & - & - \\
\hline LAMDA & - & $\bar{D}$ & $\overline{\mathrm{DF}}$ & - & 1.2684 & 0.2123 & 5.97 & 0.00 \\
\hline & statistics & P-value & statistics & P-value & DF & \\
& & & & & & & & \\
\hline $\mathrm{R}^{2}$ & 0.6015 & & - & - & 0.7985 & - & - & - \\
\hline LR & 86.959 & 0.000 & 1 & - & 85.92034 & 0.000 & 1 & - \\
\hline AIC & -8 & - & - & - & -6 & - & - & - \\
\hline SC & 13.6048 & - & - & - & 10.2036 & - & - & - \\
\hline
\end{tabular}

Second, for the regression coefficients of the three models, none of the coefficients in the SLM is significant, but almost all of them are significant in the SEM and the OLS at the 10\% significance level. Among them, the coefficient of the variable, fiscal transparency, is bigger than that of OLS; therefore, it can be inferred that the classical linear regression model underestimates the effect of fiscal transparency on FDI. Then, the signs of the coefficients of all the variables are in line with the 
economic significance, that is, there exists positive effect of fiscal transparency on FDI. For the numerical value of the coefficient, other things being unchanged, $1 \%$ change of fiscal transparency would cause $1.4686 \%$ change of FDI; it can be therefore concluded that in China, improving fiscal transparency can play a positive role in optimizing investment environment, and attracting foreign capital. Compared with the regression coefficient of the fiscal transparency, the contribution of GDP per capita to fiscal transparency is almost $1 \%$ higher than that of FDI, which in a sense indicates that in China economic development has higher effect on attracting of foreign investment than fiscal transparency does.

Third, for the estimated result of the SEM, the coefficient reflecting the influence of spatial dependence on the error term is 1.2684, significant at the $1 \%$ significance level. This result is consistent with the Moran's Index result of the global autocorrelation test.

\section{Conclusions}

Form the spatial econometric analysis result, fiscal transparency has a significant positive spatial correlation between the provinces and cities concerned, that is, if a province has relatively high fiscal transparency, its surrounding provinces will also have high fiscal transparency, and if a province has relatively low fiscal transparency, its surrounding provinces will also have low fiscal transparency. FDI in China has spatial dependence on fiscal transparency; therefore, it is biased for the traditional linear regression method to analyze the effect of fiscal transparency on the FDI.

By comparing the result derived from the OLS, SLM and SEM, it can be seen that the spatial effect of fiscal transparency on FDI of China is reflected in the error term; the spatial effect of FDI in China is not caused by themselves' interaction but by the impact of the overall characteristics of a certain region's fiscal transparency and GDP per capita on the local region and the adjacent regions. For the estimated coefficient of the SEM, 1\% change of fiscal transparency would cause 1.4686\% change of FDI.

In China, improving fiscal transparency can play a positive role in optimizing investment environment, and attracting foreign capital. Therefore, if the government wants to attract foreign investment through improving fiscal transparency, first of all, it needs to ensure that its fiscal information is transparency, for creating a good investment environment is good for attracting potential foreign investors; second, the empirical study of this paper discovers that, for each percentage change of fiscal transparency, the marginal effect of FDI can increase by 1.4686, so the local governments should take measures of improving fiscal transparency as its reform direction; third, the fiscal information released by the government is supposed to be reliable, and the investment policy needs to be persistent, so that investors can analyze and manage their investment matters more effectively.

\section{Acknowledgment}

This paper belongs to the project of the "Anhui Province Educational Department Key Projects”, No. SK2014A436, Effect of Large Data on Corruption from the Perspective of Fiscal Transparency.

\section{References}

[1]. G. Kopits, J. Craig, "Transparency in government operations". IMF Occasional paper, 1998/158.

[2]. T. Vishwanath, D. kaufmann, "Toward transparency: new approaches and their application to financial markets”, The World Bank Research Observer, 2001.

[3]. J. Z. He, “Theory source of budget transparency and international practice”, Journal of China National School of Administration, 2008, (02):P91-97. (In Chinese)

[4]. Y. Li, "Transparency of fiscal information is the basis for budget monitoring and management”, Public Finance Research, 2010, (06):P13-16. (In Chinese) 
[5]. J. Ferejohn, Accountability and Authority: Towards a Model of Political Accountability, 1999:131-153.

[6]. M. Ferretti, G. Maria, "Good, bad, or ugly? On the effects of fiscal rules with creative accounting”, IMF Working Paper, 2000/172.

[7]. M. Shi, J. Svensson, “Conditional political budget cycles”, CEPR Discussion Paper, 2002, No. 3352.

[8]. F. Hameed, "Fiscal transparency and economic outcomes". IMF Working Paper, $\mathrm{WP} / 2005 / 225$.

[9]. M. Jarmuzek, "Does fiscal transparency matter? The evidence from transition economies. https://iweb.cerge-ei.cz/pdf/gdn/RRCV_77_paper_03.pdf. 2006.

[10]. N.Andreula, A.Chong and Guillén, "Institutional quality and fiscal transparency", Inter-American Development Bank Working Paper, 2009.

[11]. M. Petrie, "Promoting fiscal transparency: the complementary roles of the IMF, financial markets and civil society”, IMF Working Paper, 2003.

[12]. R. G. Gelos, S. J. Wei, “Transparency and international investor behavior”, IMF Working Paper, 2003.

[13]. M. Na, Y. Li, "Research on the construction of fiscal transparency evaluation system and its test-based on provincial level survey data of China”, 2nd International Conference on Education, Management and Social Science, 2014. (In Chinese)

[14]. L. Anselin, Spatial Econometrics: Methods and Models, Kluwer Academic Publishers, 1988. 